\title{
الاغتراب في شعر المعتمد بن عباد
}

\section{م.م أحمد عبد الحميد رسـن الأسـدي

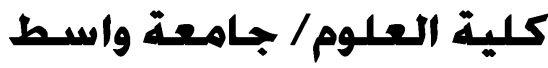 \\ ملخص:}

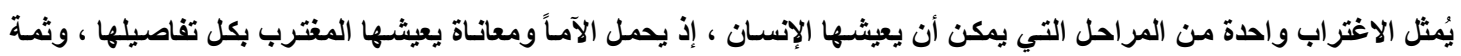

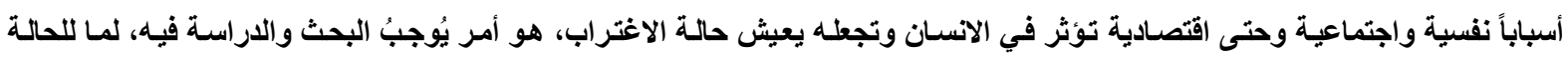

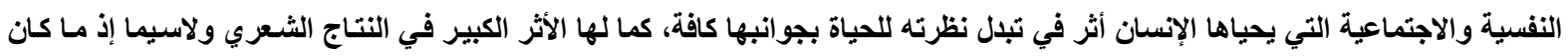

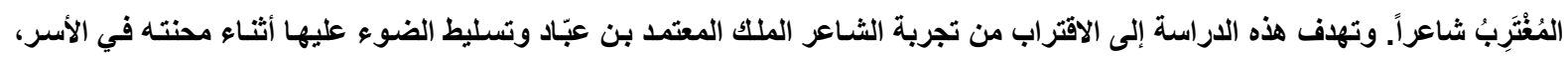

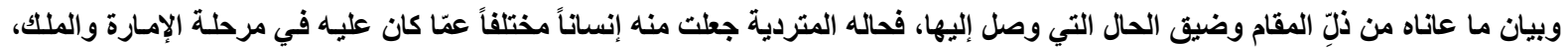

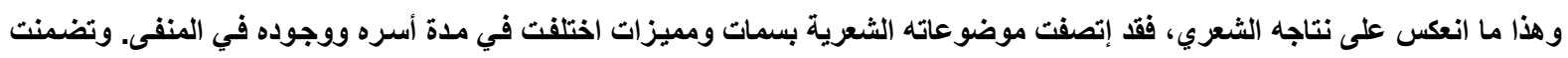

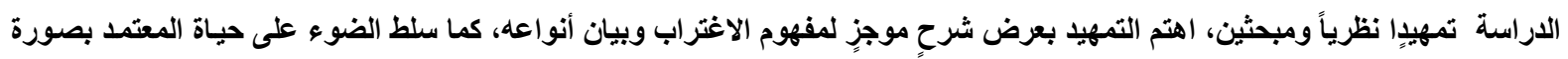

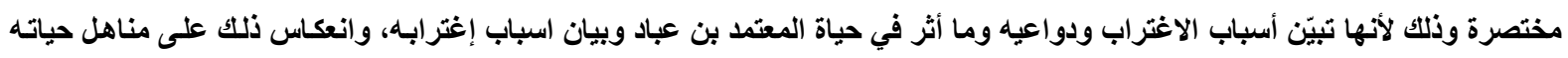

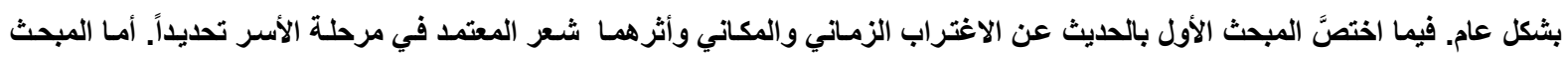

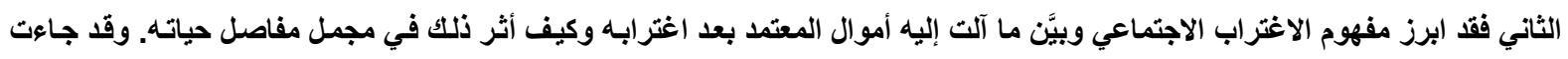

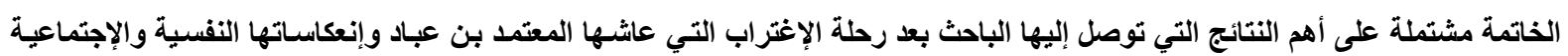
على مفاصل مهمة من حياته ونتاجه الثبري.

ملخص البحث باللغة الإنكليزية

This study aims at drawing closer to the experience of the poet King Al-Moatamed bin Abbad and shedding light on it during his ordeal in captivity and the suffering he suffered. On poetry, his hair during his reign had features that were not in his poetry during his captivity and exile

The alienation is a distinctive stage in the life of the person because it carries with it pains that are clear evidence of the suffering experienced by its owner in all its details. Man does not resort to alienation without a psychological crisis, which brought with it and combined with life and social reasons that influenced it strongly. The alienation in the life of any person has reversed From the state of kings to the case of the prisoner is a matter of research and study, because of the psychological state and social life of man affected the change of his view of life in all aspects, and have a significant impact in the poetic output, especially since the expatriate poet.

\section{التمهيد- مفهوم الإغتراب وملاميح من حياة الشـاعر}

من مقتضيات هذه الدر اسة كان لابد من تقديم لمحة موجزة عن مفهوم الاغتر اب في اللغة والاصطلاح، وتقديم نبذة عن حياة الثـاعر وأسباب إغتر ابه والمر احل الزمنية التي عاثها في خضم تلاك المرحلة.

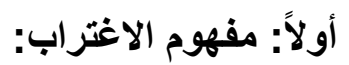

الاغتر اب ظاهرة قديمة رافقت الإنسان منذ وجوده على الأرض، ونشـأت مـع تشكل المجتمعات، وفي

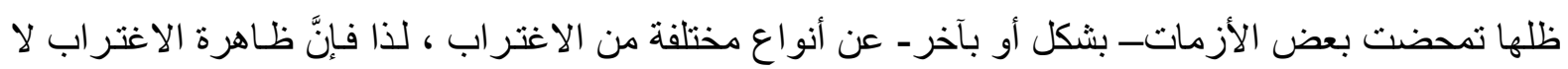
ترتبط بمجتمع معين، إنما هي ظاهرة إنسانية يمكن أن تلاحظ وتدرس في كل أنماط الحياة الاجتماعية، إذ إنها

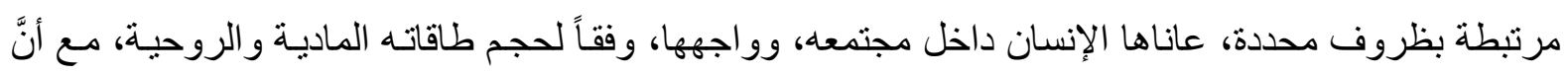
شـدة هذه الظـاهرة ومدى شـيو عها نسبيان، ويختلفـان بـاختلاف الثقافـات و الظـروف الاجتماعيـة، و التاريخيـة، 
و الاقتصـادية، والسياسية، لذا فهـي تقود الأفر اد إلى التهـرد حينـاً، أو تفضـي بهم إلى الاستسـلام أو الانعـزال و الانكفاء على الذات أحياناً أخرى.

$$
\begin{aligned}
& \text { والاغتر اب في اللغة كما جاء في لسان العرب تحت مادة ( غ ر ب ) : } \\
& \text { الغَرْبُ: الذهاب والتنحي عن الناس. } \\
& \text { وأغرب وغربَة، وأغربَه: نحّاه. } \\
& \text { و الغرَبة والغرَب: النوى و البعد، تغرَّب: ابتعد وفارق. } \\
& \text { التغريب: النفي عن البلد. } \\
& \text { و غريب: بعيد عن وطنه، و الجمع غرباء، والأنثى غريبة ... } \\
& \text { و الاغتر اب: افتعال من الغربة. } \\
& \text { وأغرَبَ الرجل: صلار غريباً ... ورجل غريب: ليس من القوم. } \\
& \text { والاغتر ابُُ هو افتعالُ الغربةِ والإجبارُ عليها لسببٍٍ ما.' }
\end{aligned}
$$

و الملاحظ أنَّ هناك فرقاً واضحاً بين الغريب: الذي يعيش حالة البعد عن وطنه و أهله، وقومـه وأرضـه،

$$
\text { و المُغترِب: الذي هو من قصد الغربة قسر اً. }
$$

أما في الاصطلاح فقد حظي مفهوم الغربـة باهتمام كبير في أوسـاط الفلاسفة، وتباينت مفاهيمه تبعاً لمرجعية المُنظِّرِين وتوجهاتهم الفكرية المختلفة. فقد استخدم هيجل مصطلح الاغتر اب بطريقة مختلفة، ليشير

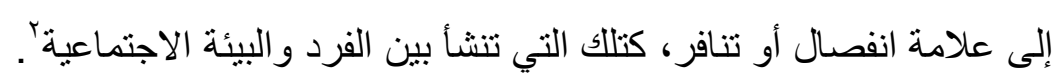

أما سارتر فيرى أنَّ لمصطلح الاغتر اب معنيين: ورد أحدهما في كتابه (الوجود و العدم)، والثناني في كتابه (نقد العقل الجدلي). أما الأول فقد كان بمعنى الاغتراب عن الذات الموضوعية، فنظرة الآخر تجعل الفرد يشعر بموضو عيته وذاتـه كما ير اه الآخر ، وفي الثاني فإن السياق الذي يتحدث في إطاره عن الاغتر اب هو السياق الماركسي، الذي يعالج علاقة الفرد بنشاطه الإنتاجي، وما يفرضه على ذاته من مشـاعر الاغتراب، فهو يصف الإنسان المغترب بأنه الفرد مغترباً ومتشيئًا.

أما فروم فيستعمل مصطلح الاغتر اب بشكل لافت للنظر، إذ يصف بـه علاقة الثخص بنفسه، و علاقته بـالآخرين، و علاقته بأتشياء أخرى كثيرة، مـن قبيل الحب و الفكر ، والأمسة و الثقافة المعاصـرة، وأهم مجـالات

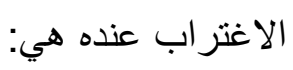

ا - الاغتر اب عن الآخرين: حيث يـرى أنَّ جوهر مفهوم الاغتراب هو أنَّ الآخرين يصبحون غربـاء بالنسبة إلى الإنسان المغترب. 
r- الاغتر اب عن المجتمع: فالمجتمع المُغترِب يعني أنَّ هيكله قد أُقيَ على نحوٍ يميل معه إلى جعل الأفراد مغتربين بهذه الطرق المختلفة. r- الاغتراب عن الذات: الذي يعرّفه في كتابه (المجتمع السوّي) بأنه: نوعية من التجارب أو الميزات التي يعايش فيها المرء ذاته باعتبار ها غريبة عنه، و هذا يعني أنه أخفق في أن يكون ذاتاً أصيلة؛.

ويرى سكولز أنَّ الاغتر اب "ينشأ من خبرات الفرد التي يمر بها مـع نفسه، ومع الآخرين ، و لا يتصف

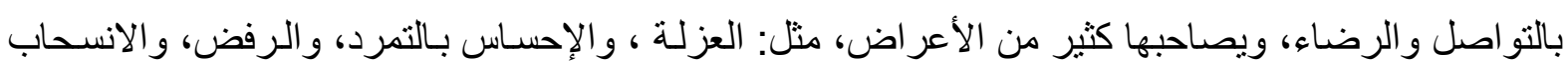

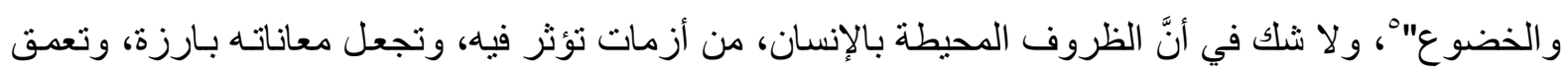
إحساسه بالاغتر اب في مختلف أنو اعه، ممّا يجعل الاغتر اب حالة يعبر فيها الفرد عن انفصـاله عن ذاته، حيث

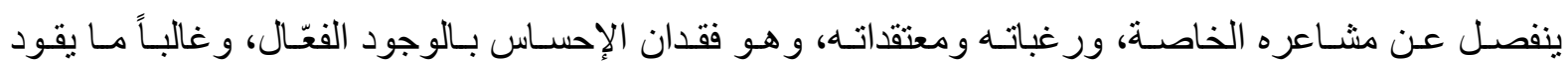

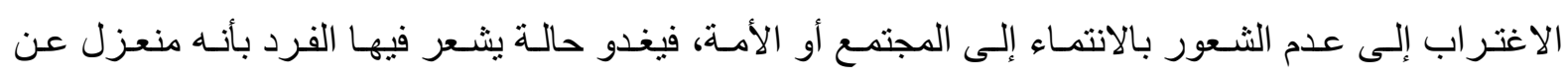

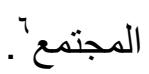

ثانياً : حياة المعتمد بن عباد مراحل ومحطات:

سيرة الإنسان هي ثمار معطيات كثثرة ومر احل مختلفة وتقاليد استشرت في تربة التاريخ مسابقة وجوده فساير ها أو غاير ها في ملابسات البيئة و المحيط من زمان الإنسان ومكان. إنَّ المعتمد ليس إلا فرداً متميز اً ومثالاً بارزاً لأرستقر اطية السيف والمال في مجتمع ملوك الطو ائف في بلاد الأندلس و هي صفة تلتصق بأغلب الحكام. ولد المعتمد بن عباد في بلدة باجـة غربي الأندلس عام اس؟گهوأبوه هو الملك المعتضد عملاق ملوك الطو ائف، وبقي المعتمد في قصر أبيه يعيش حياة الترف والانغماس في الملذات، عُيّن حاكمـاً على سهلب وهو بهو في سن الرابعة عشر من حياته، وفي عام .0؟ه عيّن ولياً للعهد، وبعدها بإحدى عشرة سنة تولى عرش إثبيلية بعد وفاة أبيه، ووجد نفسه فوق عرش وطيد الأركان متين البنيان، ينعم بالاستقرار و النظام، وبعدها بمدة وجيزة

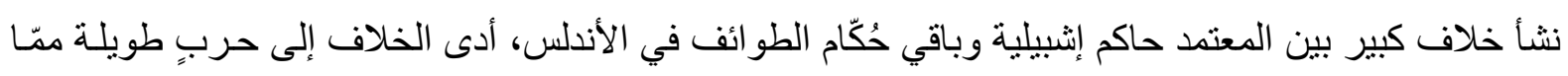

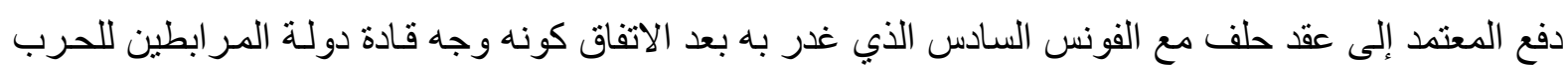
على المعتمد ، ممّا جعل المعتمد في مو اجهة حـادة مع كل من حوله، وغزا الفونس السـادس التخوم و الجبهات الأندلسية وعاث فيها فساداً من قتل وحرق ، وكان يوسف بن تاثشفين قائداً لهذه المعركة التي سُميت بمعركة

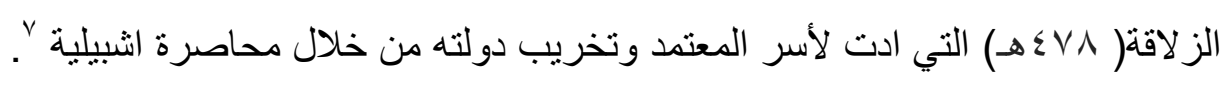
اتصل المعتمد بملوك الطو ائف طالباً إليهم إيفاد رُسل عنهم ليكونوا وفداً يسير إلى يوسف بن تاثفين،

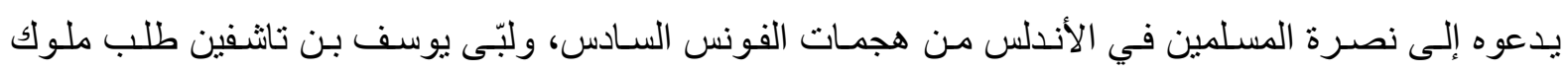
الطو ائف و عبر البحر ثم اجتمع معهم، ووحد الصفوف وانتصر في موقعة الزلاقة على الفونس ودحروه عن البلاد، وبعدها رجع يوسف بن تاشفين إلى مر اكث، و عاد ملوك الطو ائف إلى سـابق سيرتهم باستقلال كل منهم 
بمقاطعته، بل إنَّ بعضهم لم يتوانَ عن وضع يده بيد الفونس السادس، ولذا ذهب المعتمد بنفسه إلى مر اكش طالباً نجدة المر ابطين، و استجاب ابن تاشتفين للطلب، وحين وصوله رأى يوسفُ و اقعَ ملوكِ الطو ائفِ المتخاصمين

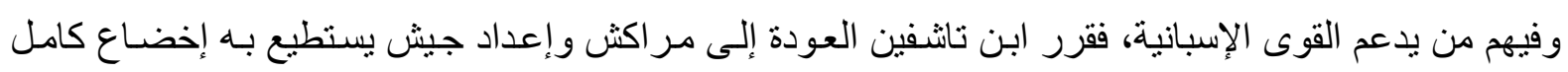

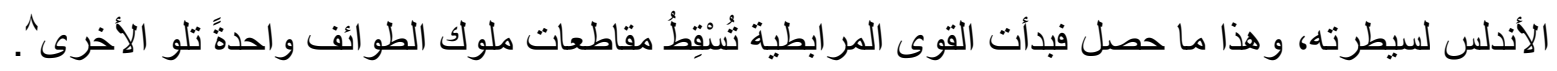
شعر المعتمد بسوء المصبر، فعاد لالتماس نصرة الفونس السادس ولكنه لم ينجده خوفاً من أن يكون هذا الأمر خديعة، وتآكلت أطر اف دولته تحت ضربات المرابطين، ودخلوا معقل المعتمد وحُمل هو وأسرته إلى طنجة مُقيداً ذليلا، ثم حُمل المعتمد إلى مركز أسره بأغمات الموجودة في المملكة المغربية. "أقام المعتمد في أغمات أسبر اً وقد ضيق عليه، كاسف البال، كسيرَ القب، يُسام سوء المعاملة، ويتجرع مرَّ الهو ان وتزدحم على خو اطره الهمومُ، وتطوف بـه ذكريـاتُ ملكه السـابق ومجده السـالف، وليس إلى جانبـه

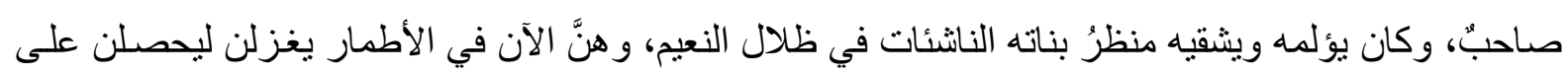
القوت

ويضاف إلى كل ذلك "ما يتوارد إليه من أنباء أبنائه ممـا يُشقل عليه عبء المصيبة ويُجسم لعينيه شبح الهول...فالمر ابطون بعد أن دكوا إثبيلية توجهوا إلى قرطبة وكان عليها ابنه المـأمون الذي ثبت على قلى قتالهم

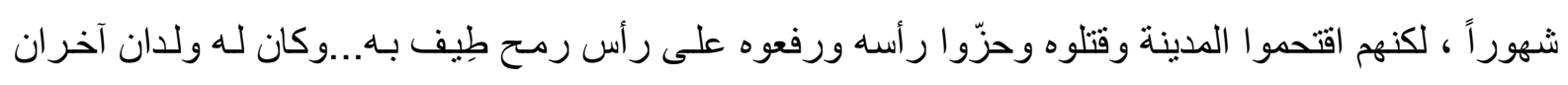
هما المعتد بالله والر اضي بالله، وكل منهما معتصمٌ بحصن منيع، وقد حمل الملك المغلوب على الكتابـة إليهما

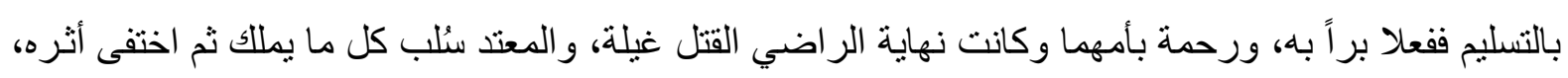

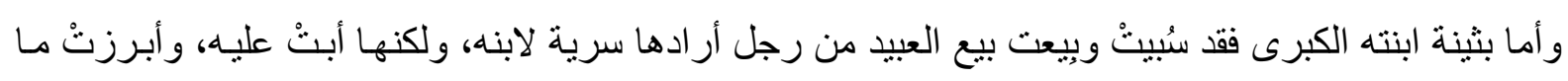

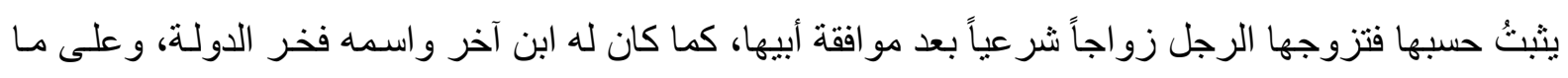

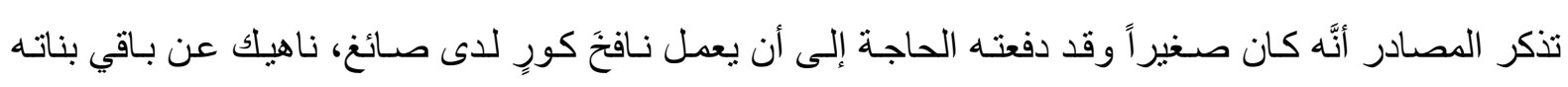

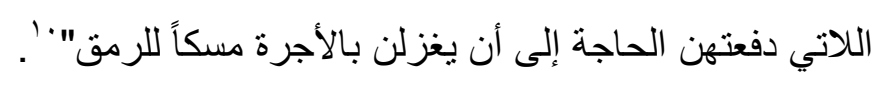

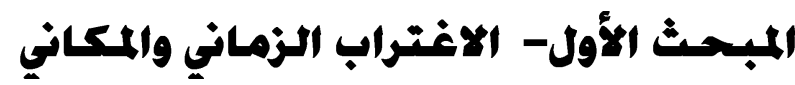

نضجت مسألة الإغتر اب عند شاعرنا نضجت بسبب المنفى ومـا طر أ من تغيير في حياة الثـاعر على المستوى الزمكاني المتأتي من بؤس النفي وألم الإنحدار بالمستوى العـام للشـاعر من الجانب الحياتي ، فضلاً عن ذلك الرؤية المأساوية التي نتجت عن هذا المنفى و انعكاساته.

أ- الاغتراب الزماني والثكوى من الزمن:

إنَّ المآسي التي مرت بالمعتمد بن عباد وفقدانـه المُلكلك و الجـاه وحياة الملوك التي كان يحياهـا جعلتُ منـه مُغتربـاً عن زمنـه الذي وصل إليه في السجن، ولعل الثكوى من تغيّر الزمـان وقسوة الدهر قديمـة قدم

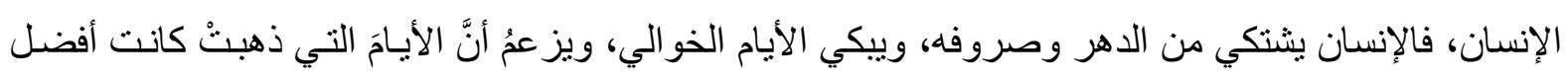
من أيامه التي يعيشها في وقته الر اهن، وهذا الزعم يخص على وجـه اليقين أوضـاعه التـي يعيثـها، ومـا تحمله

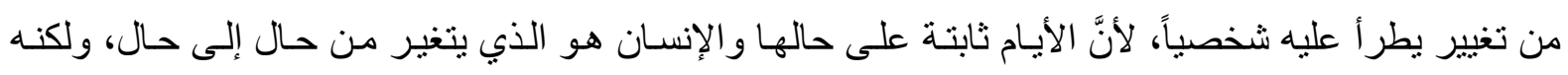


يُحمّل الأيام مسؤولية التغيير الذي ينتابه، وأكثر مـا تبدأ الثكوى من الدهر وتتعاظم في وجدان الإنسـان حينمـا

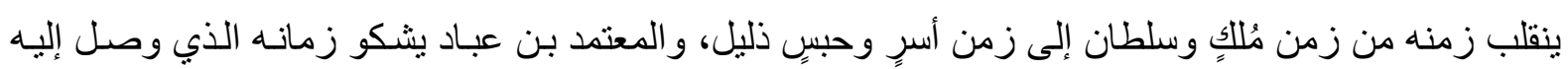

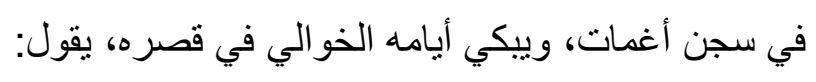

أصبحت صفراً يدي ممّا تجود به ما أعجب الحادثَ المقدورَ في رجب

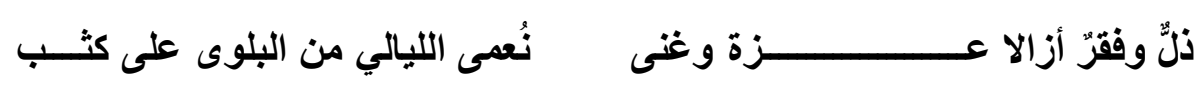
قد كان يستلبُ الجبــــــارَ مهجته بطشي ويحيا قتيلُ الفقر في طلبــي

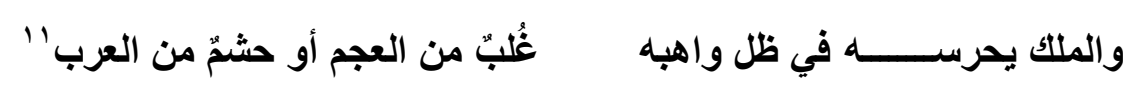

هذه الأبيات من قصيدة أرسلها المعتمد إلى رجل يُعرف بابن الزنجاري الذي سأل المعتمد أن يزوده من

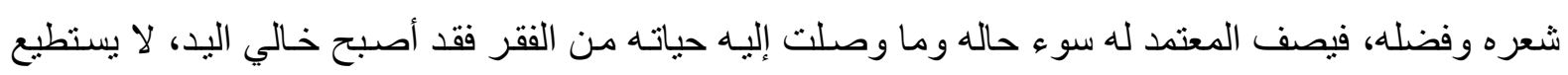
الجود والتكرم و الإحسان، فيرسم صورة فِردوسه الذي فقده في بلاد الأندلس، وذِكرُ المعتمدِ هذه الحياة الرغيدة

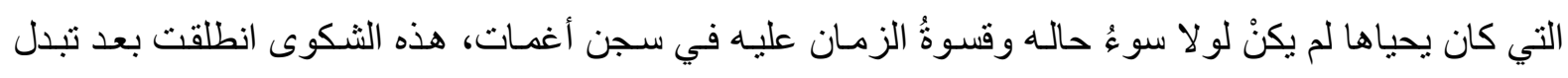
حياته، فهو الملك الذي يهابه كل جبار ، وكل فقير كان يعيش مُنعَمَاً تحت ظل جودده وكرمـه، وحاله في السجن

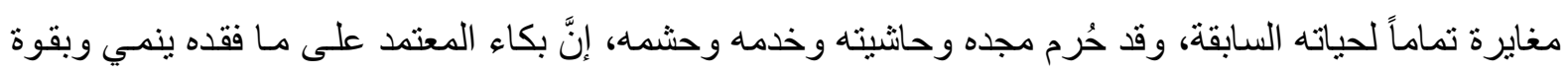

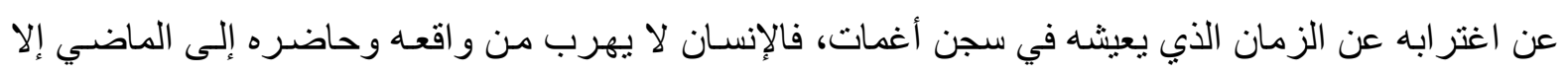
حينما يكون هذا الحاضر قاسياً مؤلماً، فيغترب عنه ويحاول نسيانه من خلال الرجوع إلى الماضي الذي يجد فيـه موطن الهناء.

وفي موضع آخر من شعر المعتمد نُلاحظ وبوضوح اغترابه وشكواه من الزمن الذي وصل إليه، فنر اه يتغنى بكرمه و عطائه الذي كان يغدقه على الناس، ثم ينتقل ليبكي حاضره الذي يكر هه، يقول:

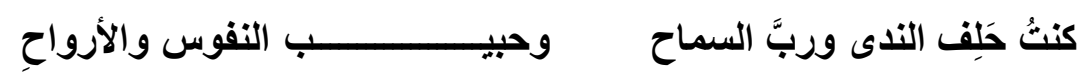

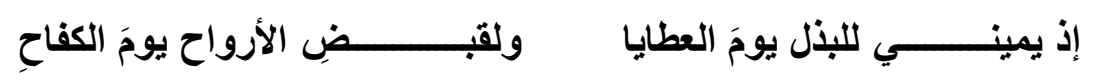

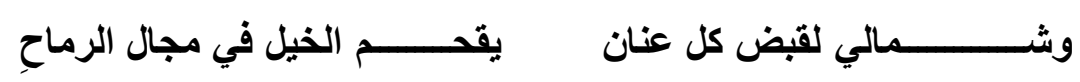

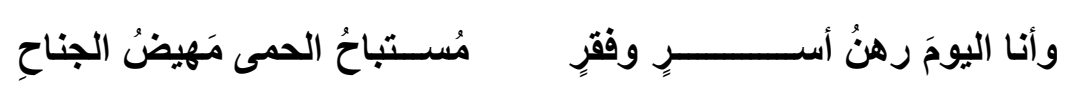

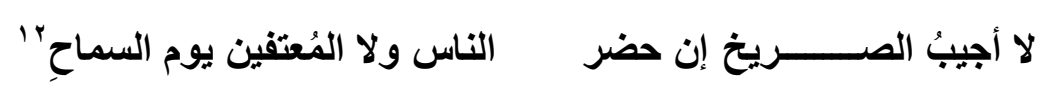

هذه الأبيات السابقة تعطينا صورة واضحة عن الحال التي وصل إليها المعتمد، فأسره منعـه إغاتنَّة من هم في حاجة له، هذه الثنيمة التي يفتخر بها كل عربي، وهو أيضـاً يقدم صورنتَه المحببة التي كان عليها بين أهله وأهل بلده، و هذه الصورة لم يذكر ها لو لا أنه أفتقدها في سجن أغمات، وهذا خير دليل على اغتر ابـه الثنديد عن زمنه الر اهن. 


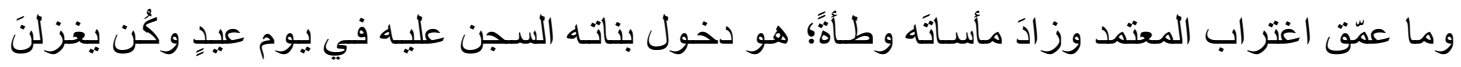

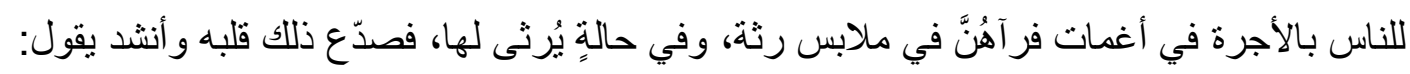

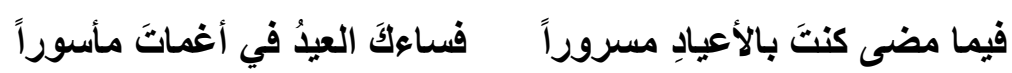

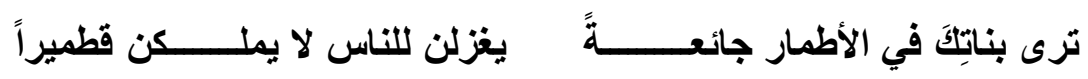

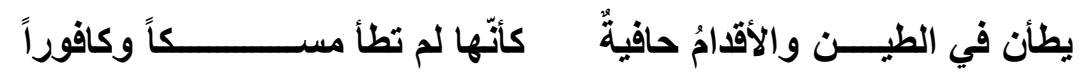

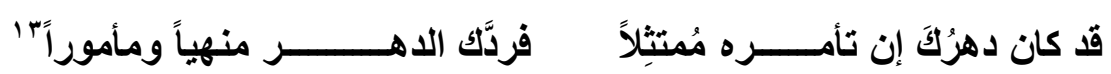
هذه الحال التي رأى المعتمد فيها بناته ز ادتُ من شكو اه واغترابه، وجعلته يتذكر الرفاه و النعيم الذي كان

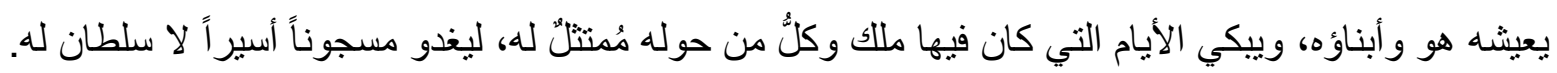

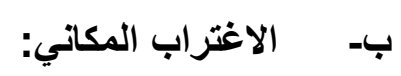
إنَّ المكان ليس حادثاً طارئاً في الثُعر العربي عامة والأندلسي خاصـة، وإنما هو رؤية خاصـة تشكلتُ

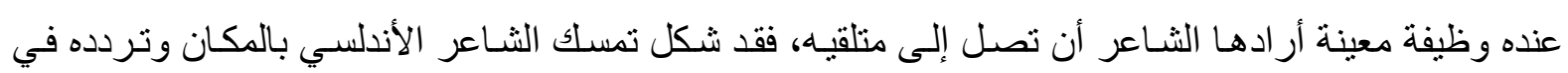

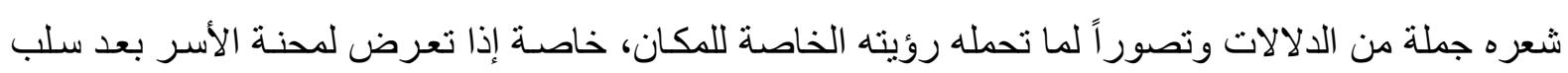

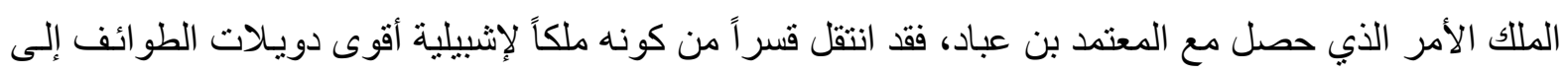
أسير أمضى ما بقي من عمره يبكي في سجن أغمات مجده ومجد آبائه'.

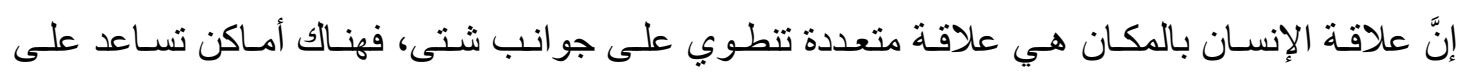

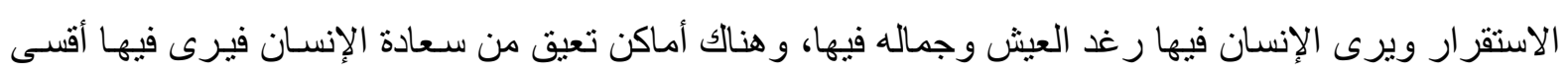

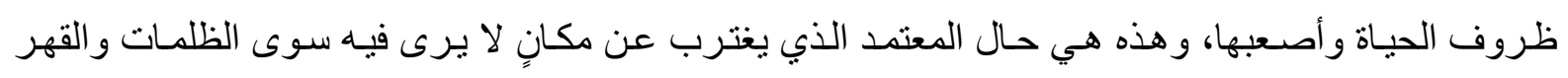

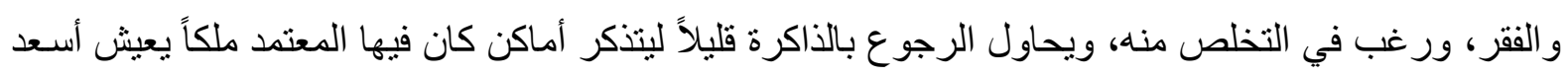

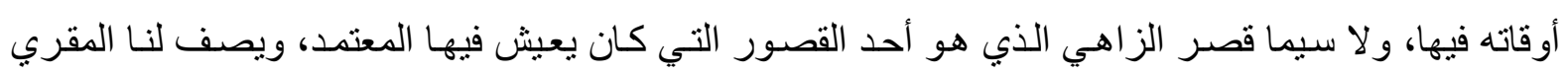

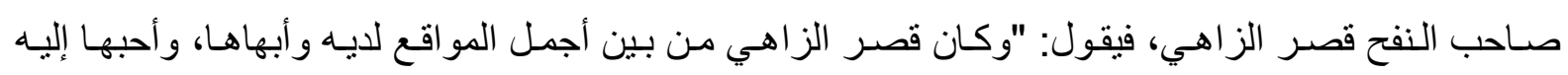

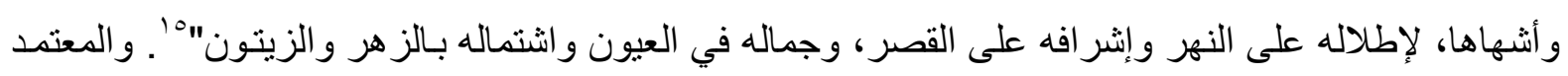

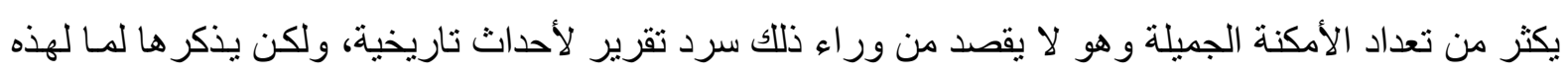

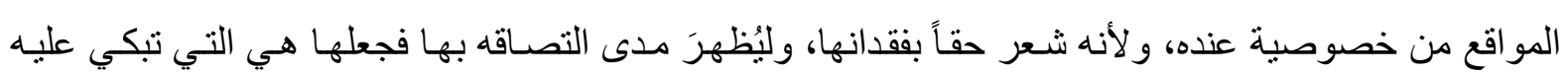

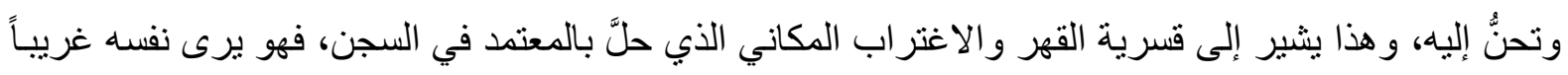

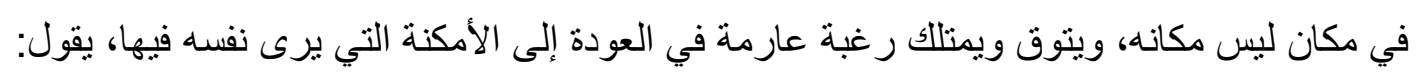

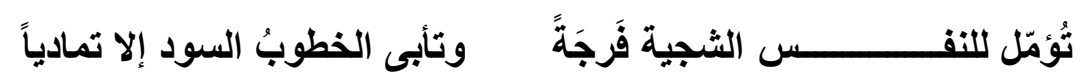

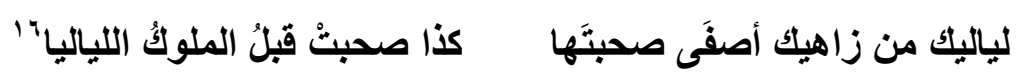


و هنا الثاعر ينسج خيوط الأمل للعودة إلى الفرح في كنف وطنه الجميل حيث العيش الرغيد، ويرغب

في الخلاص من سجنه الذي هو فيه مُغترب لمـا فيـه من القسوة والسوء، و هذا مـا يُفصـح عنه النص و ولا سيما استعمال الثاعر التناقض الذي يعطي صورة عن التناقض الذي حصل معه في حياته (الزاهي-السجن) فالزاهي هو جنته المفقودة والتي يرغب في العودة إليها، و السجن هو موطن غربته ومكان بؤسهـ وشقائه والذي أثقل روحه وبدنه، يقول أيضاً في قصيدة أخرى:

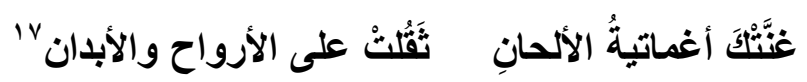

لقد كان السجن بالنسبة إلى المعتمد موطنـاً للقهر والذل و الفقر ، فقيه تتعطل الحياة، فهو يرتبط دائمـاً

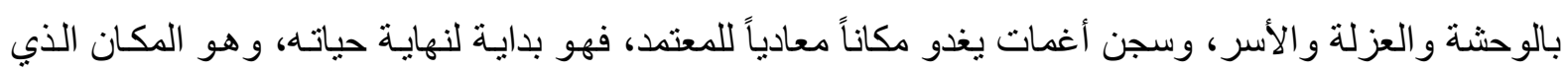

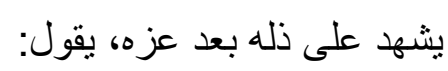

فيما مضى كنتَّ بالأعياد مسرورا فساءك العيش في أغماتَّ مأسوراًه

\section{ويقول أيضاً}

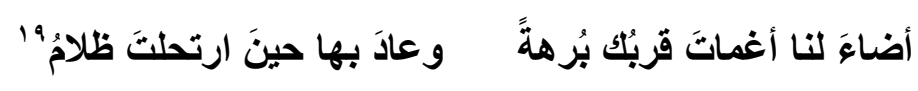
هذا المكان الذي يشتكي منه ويشعر المعتمد فيه بأنه غريب، هو مكانٌ مظلمُّ ظلمـة أطبقتْ على صدره

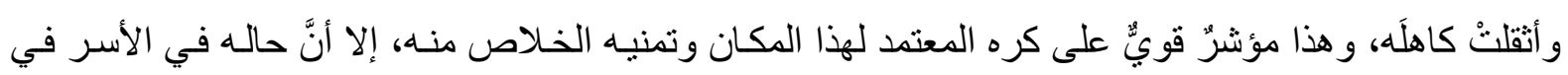

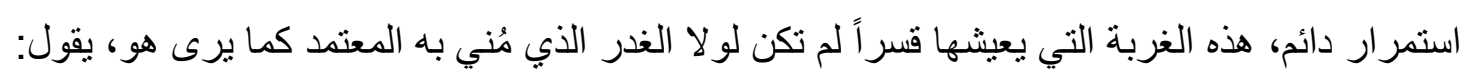

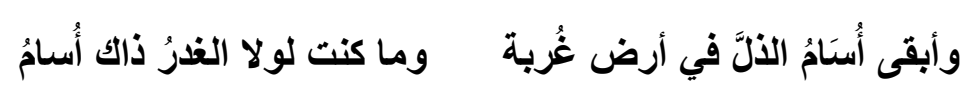

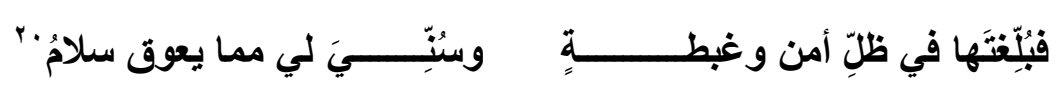

لابد لكل قارئ لهذا النص أن يشعر بعمق دلالاتها ومـا يعانيـه الثـاعر من إحسـاس بالإحباط واليأس والحزن الثديد الذي أجتاح وجدانه، وحاول بثه في ثنايا قصيدته هذه، و هذا الحزن وذلك التشـاؤم يعدان مظهراً

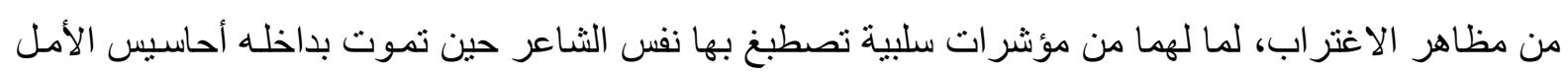
و التفاؤل، وما يضفي عليه الو اقع من نظر ات سوداوية تلون حياته بقتامة لونها، وهذه النظرة سيطرت على حياة المعتمد في السجن، وظهرت جليّاً في شعره.

\section{المبسحث الثناني- الاغتراب الاجتمعامي}

الكثير منا قد يعيش مرحلة الإغتر اب الاجتماعي، إلا أنَّ هذه المرحلة عند الثـعر اء تأخذ بُعداً آخر من خلال تجسيدها شعرياً بروح سجلت في مكامنها ملامح ألم وجزع لا يمكن للإنسان غير الثاعر تجسيدها والبوح بخلجاته. 


$$
\text { الاغتراب عن الانيا وتمني الموت: }
$$

إنَّ الغربة تنطوي في أساسها على الاستسلام للو اقع الذي يعيش فيه الإنسان و عدم مقدرته على التغيير، الإحساس بعدم الانسجام فيحاول الإنسان الانسحاب من هذا الو اقع و الزهد في حياته، ويتمنى إنهاء هذه المأسـاة

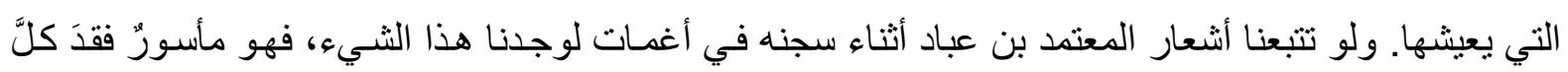

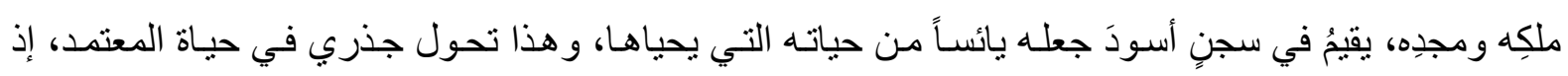
غدتْ الدنيا في نظره دنيةًة سوداء، فيريد التخلص منها، و عندما كان الوزير أبو العـلاء زهر بن عبد الملك ولك بمر اكث قد استدعى أمير المسلمين لعلاجه، فكتب إليه المعتمد راغباً في علاج بعض كر ائمهه ومطالعـة أحو الها

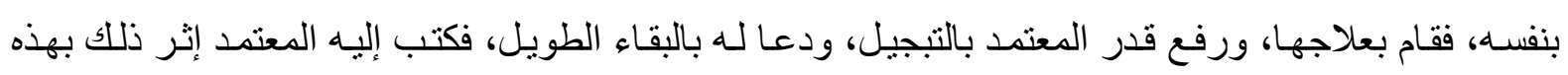

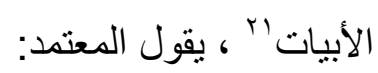

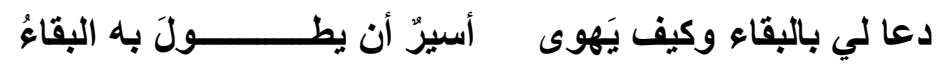

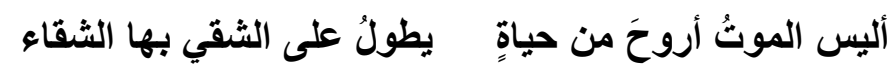 فمن يكُ من هواه لقاءُ حبٍ} إنَّ الدعوة إلى نبذ الدنيا ومباهجها وتحقير ها إنما هي سلوك انكفائي و انسحاب إجباري من الحياة يسميه المحللون الانتحار النفسي ويُعرف بأنه (نوع من الانتحار غير الصريح) حيث يزهد هد البعض في الحياة تمامـاً ويبغضونها بَ، وقد تطور هذا النبذ إلى تمني الموت، إنَّ المعتمد إذ ينزعج من دعاء صديقه ويتعجب منه لم يكن

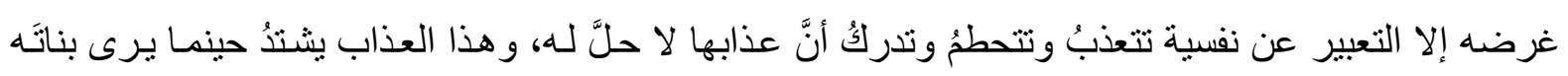

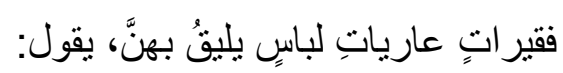

أ أرغبُ أن أعيش أرى بناتي عَوارِيَ قد أضرَّ بها الحفاعُ

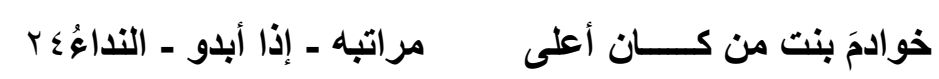
وأمام هذا العذاب و هذه الحال المزرية نتنتعل نيران اليأس في قلب المعتمد، فلا يجذُ أفضل من تمني

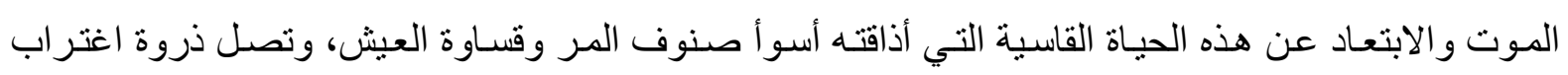

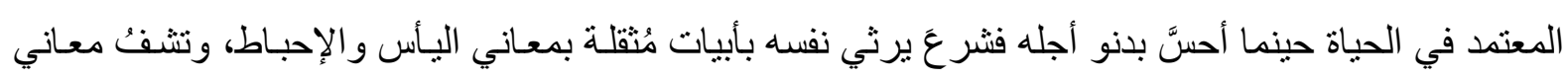
الزهد من الحياة التي لم يعذْ يطيقُ وجودَه فيها، يقول:

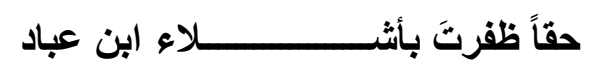
بالخصب إن أجدبوا بالريّ للصــادي

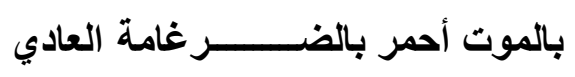
بالبدر في ظُلَم، وبالصدر في النادي

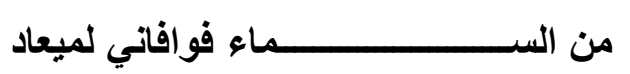

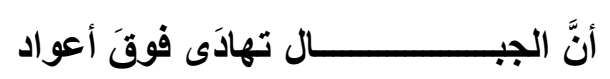

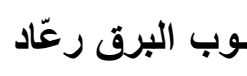
روّاك كُلْ قط انُ
قبرَ الغريبِ ســـــــاكَّ الرائحُ الغادي

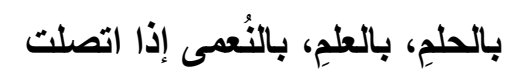
بالطاعنِ الضاربِ الرامي إذا اقتتلوا

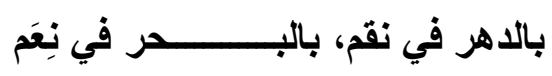

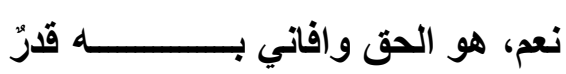

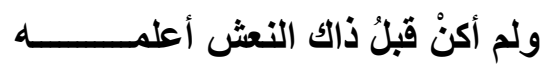
كفاتك فارفُق بما اسـتُودئ دعت من كرم 


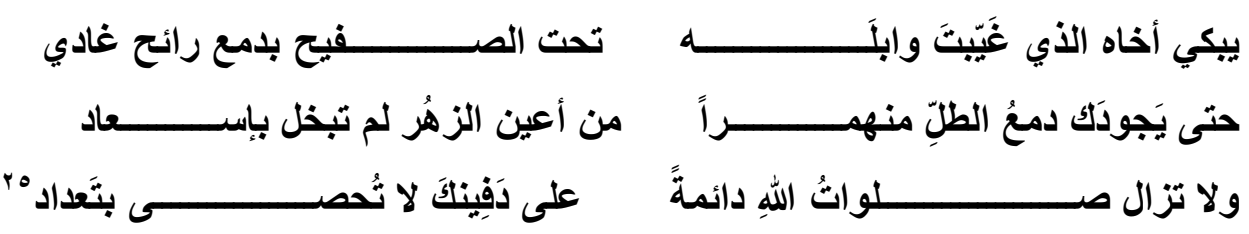

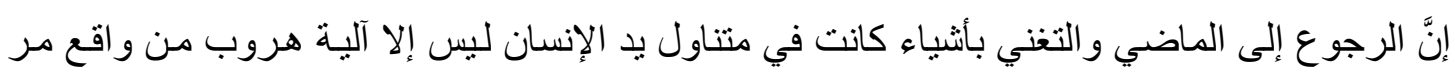

سيء، فالمعتمد يتغنى بنفسه ويسهب في ذكر محاسنه، وكل الخصـال الحميدة فيه، ويفتخر بكونـه فارسـاً يبغي الموت بساحات المعارك ولكن القدر اختار له الموت في سجنه، وينتقل ليرى بنفسه أنهه جبلٌ دُّك فهوى متهادياً، لكنه ييقى فوق ذلك المعتمد بن عباد الملك الذي عرفه الناس وأحبوه.

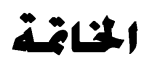

كانت رحلة البحث مـع الغربـة في شعر المعتمد بن عباد ممتعـة بالقدر الذي كانت فيه مأسـاوية. وقد

خلص البحث إلى النتائج الآتية: - (

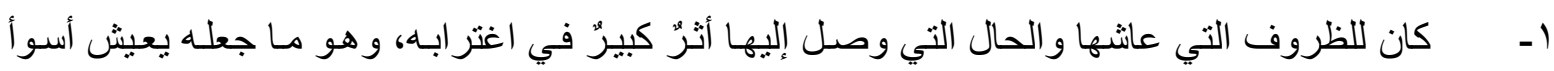
لحظات عمره ، و ولا سيما في سجن أغمات. r- - كان المعتمد في بدايـة أمره مغتربـاً عن زمانـه الر اهن في الأسـر ويحـاول استعادة تاريخهـ المجيد، وبعدها ينتقل للتعبير عن اغتر ابه في المكان الذي أنهى حياته به.

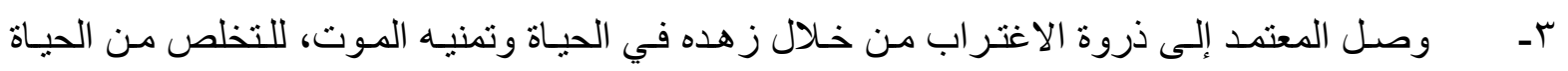
القاسية التي كان يحياها. عـ - تميز نتاجه الشعري بمفردات الأسى و الألم، وبالتر اكيب الموحية بالحزن و الندم. هـعلى الرغم من اغتر اب المعتمد ومعاناته إلا إنَّ شعره لم يخلُ من خطاب الملوك وأسلوبهم في التعامل و هذا ما ينمي عن نفس ملك وفارس من سلالة ملوك. هوامش البحثث

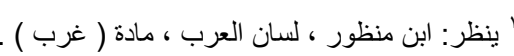

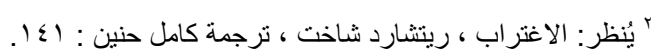

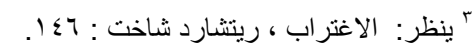

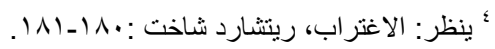

• الاغتر اب اصطلاحاً ومفهوماً، سعد بلعاد:

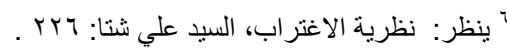

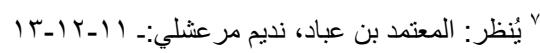

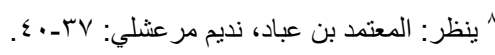

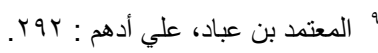

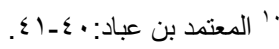

"ديوان المعتمد بن عباد (ملك إثبيلية) ، جمعه وحقهه: حامد عبد المجيد وأحمد أحمد بدوي: rو.

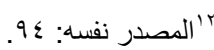

ז' المصدر نفسه : . . 1 1 .1. 


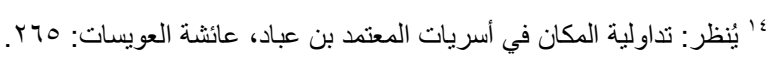

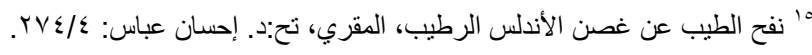

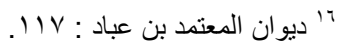

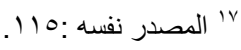

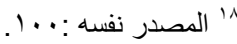

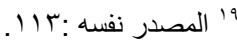

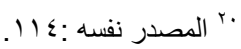

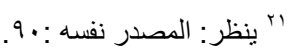

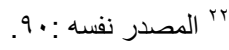

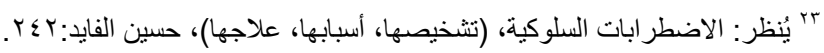

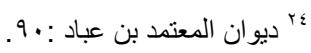

97 : 970

\section{المسادر والمراجي}

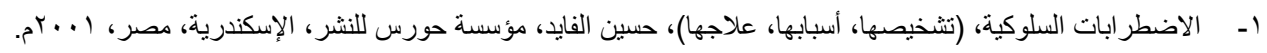

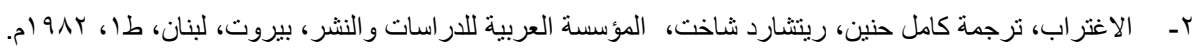

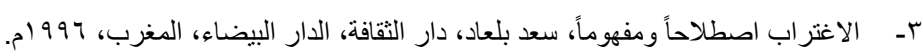

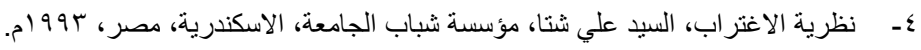

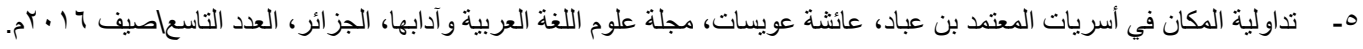

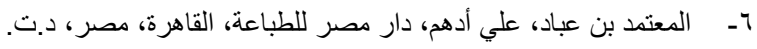

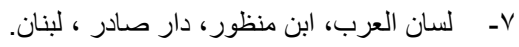

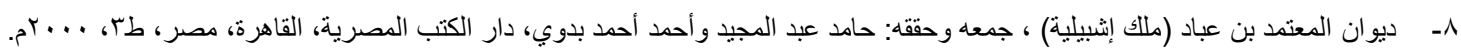

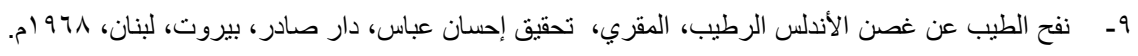

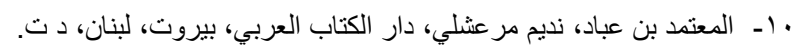

